Original Paper http://ajol.info/index.php/ijbcs http://indexmedicus.afro.who.int

\title{
The fall armyworm Spodoptera frugiperda (J.E. Smith), a new pest of maize in Africa: monitoring, damage evaluation and identification of natural enemies on production areas of Senegal
}

\author{
Awa NDIAYE ${ }^{*}$, Mariama FAYE ${ }^{1,2}$, Ibrahima BA $^{1,2}$, Ibrahima DIALLO ${ }^{1,2}$ and \\ Pape Mbacké SEMBENE ${ }^{2}$
}

\author{
${ }^{1}$ Institut Sénégalais de Recherche Agricoles (ISRA) / Centre pour le Développement de l'Horticulture (CDH), \\ routes des hydrocarbures, Bel Air, Boite postale 3120 Dakar-Sénégal. \\ ${ }^{2} U C A D$, Faculté des Sciences et Techniques (FST), Département de Biologie Animale, Boite postale 5005, \\ Dakar Fann, Sénégal. \\ *Corresponding author; E-mail: awa.ndiaye@isra.sn, Tél: +221 (77 508 39 48).
}

\section{ACKNOWLEDGMENTS}

We gratefully acknowledge the Korea-Africa Food \& Agriculture Cooperation Initiative (KAFACI; Management of Fall Armyworm (Spodoptera frugiperda) for sustainable food security in Africa), International Technical Cooperation Center, Rural Development Administration, and Republic of Korea.

\begin{tabular}{lll}
\hline Received: 23-04-2021 & Accepted: 16-11-2021 & Published: 31-12-2021 \\
\hline
\end{tabular}

\begin{abstract}
The fall armyworm (FAW) Spodoptera frugiperda (J.E. Smith), an invasive pest of cereal crops in Africa, poses a real threat to food security in sub-Saharan African countries where cereals are the staple food. Since its appearance in Africa in 2016, the FAW has invaded almost all African countries due to its great dispersal capacity. Because of its resistance to a number of chemical pesticides but also the risks associated with the use of these, the search for an alternative method becomes essential. In order to report on the incidence of this pest and explore its associations with native natural enemies, a monitoring study of $S$. frugiperda populations, its damage as well as its natural enemies was carried out during the period of August to September 2020 in corn fields of two agro-ecological zones of Senegal and in the laboratory. Monitoring results show a heavy infestation with rates of up to nearly $75 \%$ of defoliated plants and more than $60 \%$ of attacked ears. The damage recorded remains low overall (score below 3/9). A wide range of auxiliary insects (17 families) made up of parasitoids and predators were identified in the field and in the laboratory as well as an endoparasitic nematode with a parasitism rate of $38.46 \%$ and a fungus in one of the sites. These results pave the way for the development of an approach to control CLA with these biological agents.
\end{abstract}

(C) 2021 International Formulae Group. All rights reserved.

Keywords : invasive pest, cereal crops, food security, incidence, Senegal.

\section{INTRODUCTION}

The fall armyworm (FAW), Spodoptera frugiperda (J.E. Smith, 1797), is a polyphagous insect native to tropical and subtropical
America (Ayala et al., 2013; Sharanabasappa et al., 2018). The invasive FAW was first reported in West Africa in late 2016 (Goergen et al., 2016); in early 2017, the pest invaded 
sub-Saharan Africa including Senegal (Brevault et al., 2017) and it quickly spread to different parts of the continent. Currently, its presence has been officially reported in 44 African countries (Rwomushana et al., 2018; Prasanna et al., 2018). Spodoptera frugiperda is one of the most destructive crop pests, known to attack more than 353 plants worldwide (Montezano et al., 2018; CABI, 2020), including maize, sorghum, rice, soybeans, cotton, wheat and sugar cane.

Due to its ability to spread rapidly and inflict widespread damage on several crops, the fall armyworm seriously threatens the food and nutrition security and livelihoods of millions of farm households in sub-Saharan Africa (Abrahams et al., 2017; Goergen et al., 2016; Rwomushana et al., 2018; Prasanna et al., 2018). In Africa, crop losses caused by FAW each year are approximately $\$ 16$ billion (Harrison et al., 2019). Faced with this numerous damage, control strategies have been developed against this pest, in particular the intensive application of chemical pesticides in several countries leading to the acquisition of resistance by FAW (Yu et al., 2003; Zhao et al., 2019). In general, the excessive use of insecticides and the associated risks have raised issues of farmer income management, sustainability, health and food security. This highlights the need to develop integrated pest management (IPM) strategies that meet the needs of African smallholder farmers. And this in particular through the use of biological control agents.

Therefore, the general objective of this study is to contribute to the integrated management of the fall armyworm Spodoptera frugiperda for sustainable food security. More specifically, it involved making the inventory of the infestation, assessing the damage caused and determining the association with native natural enemies of this pest.

\section{MATERIALS AND METHODS \\ Study area}

The study locations (zones) are represented according to their geographical coordinates, annual precipitation and temperature (Table 1).

\section{Niayes zone}

The Niayes, between the 200 to $500 \mathrm{~mm}$ isohyets, stretches from Dakar to Saint-Louis over a length of nearly $180 \mathrm{~km}$ and over 30-35 $\mathrm{km}$ in width and is located along the northwestern coast in the regions of Dakar, Thiès, Louga and Saint-Louis and covers an area of $3090 \mathrm{~km}^{2}$. It is characterized by closed interdune depressions with flush or sub-flush water table in the Ogolian dune system (red dunes). The microclimate is described as sub-Canarian: the relatively cool air, the higher humidity and a later rainfall season, are its characteristics unlike other parts of the country. Temperatures are on average 20 to $30{ }^{\circ} \mathrm{C}$ and the average annual rainfall is around $400 \mathrm{~mm}$ (Ndao, 2012; Camara et al., 2013, 2014b; the SONEDAFRIQUE Study Office, 2013).

\section{Central zone}

Two regions are chosen in the central zone: the Kaolack region and the Kaffrine region. In the Kaolack region, three sites were all chosen in the Department of Nioro du Rip (Keur Aly Guèye, Keur Abibou Niass and Mbitayène) and in the Kaffrine region two sites including Ndjigui (3 fields) and Boulel (3 fields). The location of the different sites is shown in Figure 1.

\section{Methodology}

This study was carried out in two stages. First, it is a field investigation during which monitoring (presence, damage intensity and natural enemies of FAW) was carried out. Insect samples were taken for further morphological and molecular characterization. Then, the Center for the Development of Horticulture (CDH), ISRA, Dakar, Senegal, formed the second, in the laboratory where the identification of collected insects and their natural enemies was made. The caterpillars brought back from the field are reared in the laboratory to identify the parasitoids that have previously infested them.

\section{Monitoring}

\section{* Installation of traps}

Delta type pheromone traps, threecomponent pheromone (Z) -tetradec-9-enyl) acetate, (Z) -hexadec-11-enyl) acetate, Z-7- 
dodecenyl acetate, Alpha Scents, Portland, OR, USA) were used to capture males of Spodoptera frugiperda.

In each of the sites (field), a trap was set up and these traps were monitored every week in order to count and identify the insects captured.

After morphological identification using the binocular magnifying glass and the identification key proposed by EPPO (2015), the captured adults of $S$. frugiperda were placed in vials containing $70 \%$ denatured ethanol.

\section{* Damage evaluation}

In the 10 fields of the two agroecological zones, the damage assessment is done every two weeks during the period from August to September 2020.

In each field, 5 rows were selected according to a W diagram. Observation covered 12 successive plants at each row. At the vegetative stage, the observation is made on the three upper leaves and the damage was evaluated according to the scale proposed by Davis et al. (1992).

The percentage of infested fields was calculated as follows:

- $\%$ of fields infested with FAW $=($ Number of fields infested with FAW) / (Total number of fields studied) $\mathrm{x} 100$

The percentage of infested plants per quadrant was calculated using the formula:

- $\quad \%$ FAW infestation $=($ Number of plants infested with FAW) / (Total number of plants observed) $\mathrm{x} 100$

\section{* Parameters observed in the field}

- The observations focused on:

- The impact of the pest on crops: determined according to the number of plants attacked out of the total number of plants sampled;

- $\quad$ The number of Spodoptera frugiperda by locality
- The degree of attack or severity was determined on the basis of a rating scale proposed by Davis et al. (1992).

- The number of natural enemies: determined by captures in the field and during monitoring of parasitized larvae.

The Maize Leaf Damage Rating Scale for $S$. frugiperda is presented in the appendix. This rating or classification scale for damage to maize leaves has been subdivided into three classes. The score of 0 to 4 is considered low, 5 to 7 is considered medium, and 8 to 9 is considered high.

\section{Larval sampling}

At each site a number of $S$. frugiperda larvae were collected for laboratory monitoring to observe the potential emergence of parasitoids. The emerged parasitoid species were identified using a binocular magnifying glass and a version 2.0 dinocapture.

\section{Inventory and sampling of predators and parasitoids of Spodoptera frugiperda}

Predators as well as $S$. frugiperda parasitoids seen in the fields were photographed using a smartphone.

Insects that were difficult to capture were photographed while those that were easy to capture were placed in $50 \mathrm{ml}$ polystyrene bottles containing $70 \%$ ethanol.

\section{Data analysis}

All of the data collected was recorded and arranged on an Excel spreadsheet and subsequently served as a database for statistical analyses. Normality tests (Shapiro-Wilk), comparison of means (Kruskall Wallis) were subsequently carried out with $\mathrm{R}$ software version 3.6.1 to see in particular the differences in the level of infestation depending on the areas but also depending on the vegetative stage. 


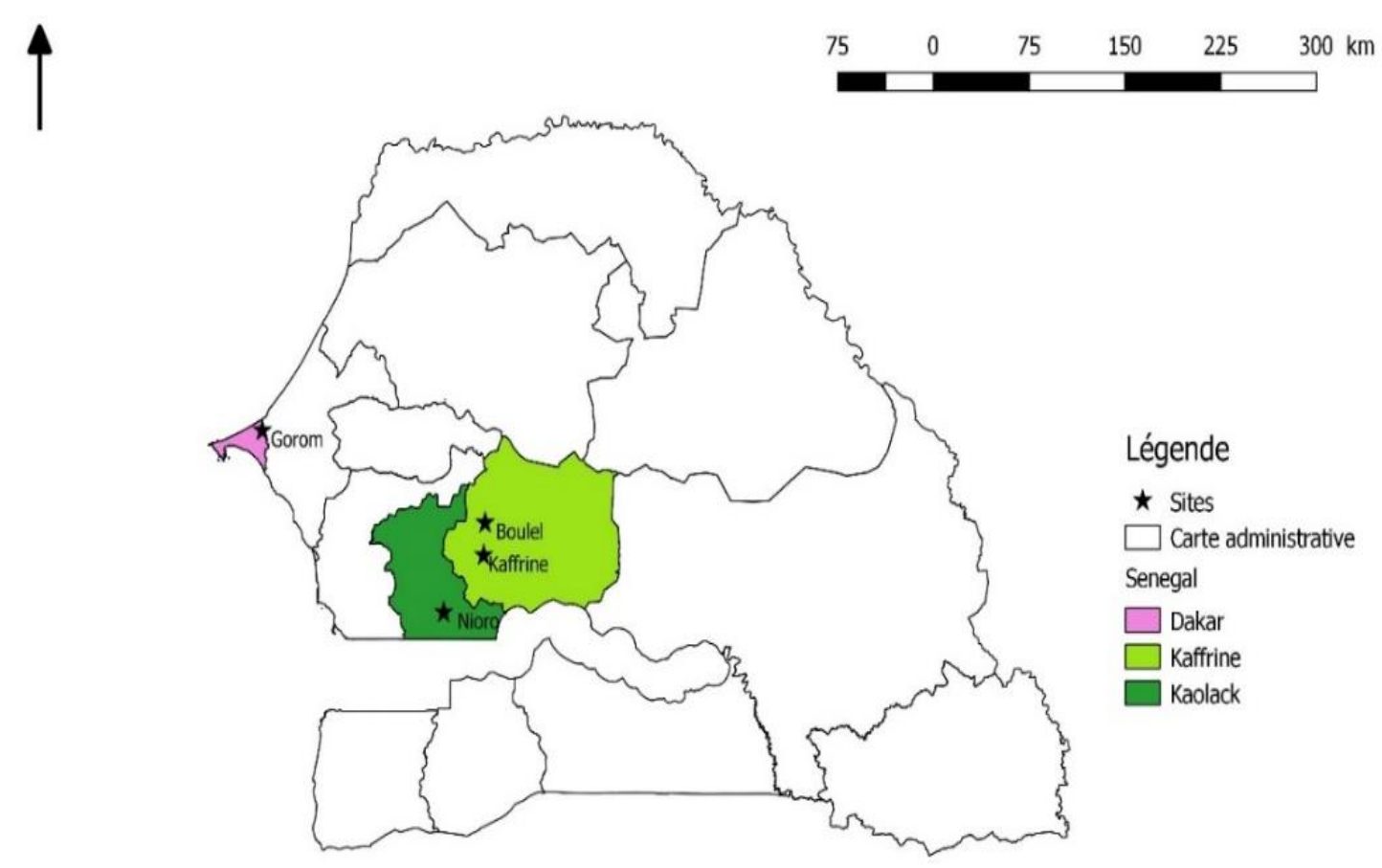

Figure 1: Location map of the study localities.

\section{RESULTS}

\section{The impact of the pest on crops}

\section{- Percentage of plants attacked by site and by stage}

The 10 fields monitored during this study in the 3 regions all recorded damage linked to attacks by $S$. frugiperda, ie a percentage of infested fields of $100 \%$. The percentages of attacks by site and according to the stage of development are presented in the following Figure 2.

Statistically significant differences are observed between sites at the vegetative stage with the Wilcoxon test which shows percentages ranging from more than $40 \%$ (Boulel sd 0,4987) to around 75\% (Gorom sd 0,4434 ) for all of the two zones (center and niayes) during the period. At the mature stage, Kaffrine records a higher percentage of plants attacked compared to the rest of the sites. The lowest percentages at both the vegetative and mature stages are noted at Boulel.

\section{- The damage level}

Assessment of the degree of defoliation and damage to the ear on the basis of the rating scale of Davis et al. (1992), Figure 3.

Statistically significant differences are observed between localities with the kruskal wallis test (chi-squared $=202.87, \mathrm{p}$-value $<2.2 \mathrm{e}-16), \mathrm{sd}=0.8537$. Damage scores assessed on the Davis scale are relatively low across all sites (mean score between 1 and 3) with the exception of one site, Gorom, where strong defoliation is noted during the vegetative stage. At the mature stage, Kaffrine records the greatest damage compared to the rest of the sites. The lowest damage, both at the vegetative and mature stages, is noted at Boulel.

- The average number of larvae by locality and adults of Spodoptera frugiperda caught by locality as a function of time (Figure 4)

Statistical analyses showed that the average number of larvae is globally low, 
however it is higher at the vegetative stage in Gorom. The Kruskal Wallis test divided the results into four groups at the vegetative stage (a, b, c and bc) where the differences are all significant ( $\mathrm{p}$-value < 2.2e-16 and an sd equal to 0,2516) except for group bc (Kaffrine Boulel and Kaffrine Nioro).

At the mature stage, the average number of larvae is much higher in Kaffrine and the significance test (Kruskal Wallis) allowed to divide the results into three groups (A, $\mathrm{B}$ and $\mathrm{C}$ ) where the differences are all significant with a p-value $=6.023 \mathrm{e}-13$ and an sd equal to 0,4261 (Figure 4).

- The average number of adults of Spodoptera frugiperda caught per trap as a function of time

Monitoring S. frugiperda populations using pheromone traps yielded the following results (Figure 5). The number of adults captured on the traps is relatively low throughout the study period, with an average maximum of around 2 individuals towards the end of culture at Nioro. In all 27 adults of $S$. frugiperda were captured on the 10 traps, the maximum number of individuals that were captured on a trap is 3 . It should also be noted that there was no trap capture in Gorom.

\section{Identifications of natural enemies of Spodoptera frugiperda}

- Predators and parasitoids of Spodoptera frugiperda

A total of 341 individuals (246 in the Central zone and 95 in the Niayes zone) were listed as potential natural enemies of Spodoptera frugiperda (Photo 1) on the host plant maize and belonging to 6 orders and 18 families including 4 unidentified families and some species of the order Araneae also belonging to 3 unidentified families in these two agroecological zones (Table 2).

Table 1: Location of study sites.

\begin{tabular}{|c|c|c|c|c|}
\hline Locality & Site & Coordinates & $\begin{array}{c}\text { Annual } \\
\text { precipitation }\end{array}$ & $\begin{array}{c}\text { Annual average } \\
\text { temperatures }\end{array}$ \\
\hline \multirow[t]{3}{*}{ Boulel } & Boulel 1 & $\begin{array}{c}15^{\circ} 32^{\prime} 39.52^{\prime \prime} \mathrm{W} ; 14^{\circ} 17^{\prime} \\
18.49^{\prime \prime} \mathrm{N}\end{array}$ & 766,3 & 29,8 \\
\hline & Boulel 2 & $\begin{array}{c}15^{\circ} 33^{\prime} 7.16^{\prime \prime} \mathrm{W} ; 14^{\circ} 16^{\prime} \\
48.58^{\prime \prime} \mathrm{N}\end{array}$ & & \\
\hline & Boulel 3 & $\begin{array}{c}15^{\circ} 33^{\prime} 55.39^{\prime \prime} \mathrm{W} ; 14^{\circ} 16^{\prime} \\
39.04^{\prime \prime} \mathrm{N}\end{array}$ & & \\
\hline \multirow[t]{3}{*}{ Kaffrine } & Ndjigui 1 & $\begin{array}{c}15^{\circ} 33^{\prime} 36.64^{\prime \prime} \mathrm{W} ; 14^{\circ} 5^{\prime} \\
0.19^{\prime \prime} \mathrm{N}\end{array}$ & 766,3 & 29,8 \\
\hline & Ndjigui 2 & $\begin{array}{c}15^{\circ} 33^{\prime} 45.21^{\prime \prime} \mathrm{W} ; 14^{\circ} 5^{\prime} \\
15.44^{\prime \prime} \mathrm{N}\end{array}$ & & \\
\hline & Ndjigui 3 & $\begin{array}{c}15^{\circ} 33^{\prime} 48.24^{\prime \prime} \mathrm{W} ; 14^{\circ} 5^{\prime} \\
15.03^{\prime \prime} \mathrm{N}\end{array}$ & & \\
\hline \multirow[t]{3}{*}{ Nioro } & Mbiteyène & $\begin{array}{c}15^{\circ} 56^{\prime} 28.62^{\prime \prime ~ W} ; 13^{\circ} 44^{\prime} \\
6.53^{\prime \prime} \mathrm{N}\end{array}$ & 766,3 & 29,8 \\
\hline & $\begin{array}{l}\text { Keur Abibou } \\
\text { Niass }\end{array}$ & $\begin{array}{c}15^{\circ} 50^{\prime} 59.13^{\prime \prime} \mathrm{W} ; 13^{\circ} 44^{\prime} \\
56.35^{\prime \prime} \mathrm{N}\end{array}$ & & \\
\hline & $\begin{array}{l}\text { Keur Aly } \\
\text { Gueye }\end{array}$ & $\begin{array}{c}15^{\circ} 50^{\prime} 40.9^{\prime \prime} \mathrm{W} ; 13^{\circ} 46^{\prime} \\
7.59^{\prime \prime} \mathrm{N}\end{array}$ & & \\
\hline Dakar & Gorom & $\begin{array}{c}17^{\circ} 9^{\prime} 21.82^{\prime \prime} \mathrm{W} ; 14^{\circ} 49^{\prime} \\
38.06^{\prime \prime} \mathrm{N}\end{array}$ & 455,1 & 28,1 \\
\hline
\end{tabular}

Climate data source: Infoclimat.fr Version 5.4 


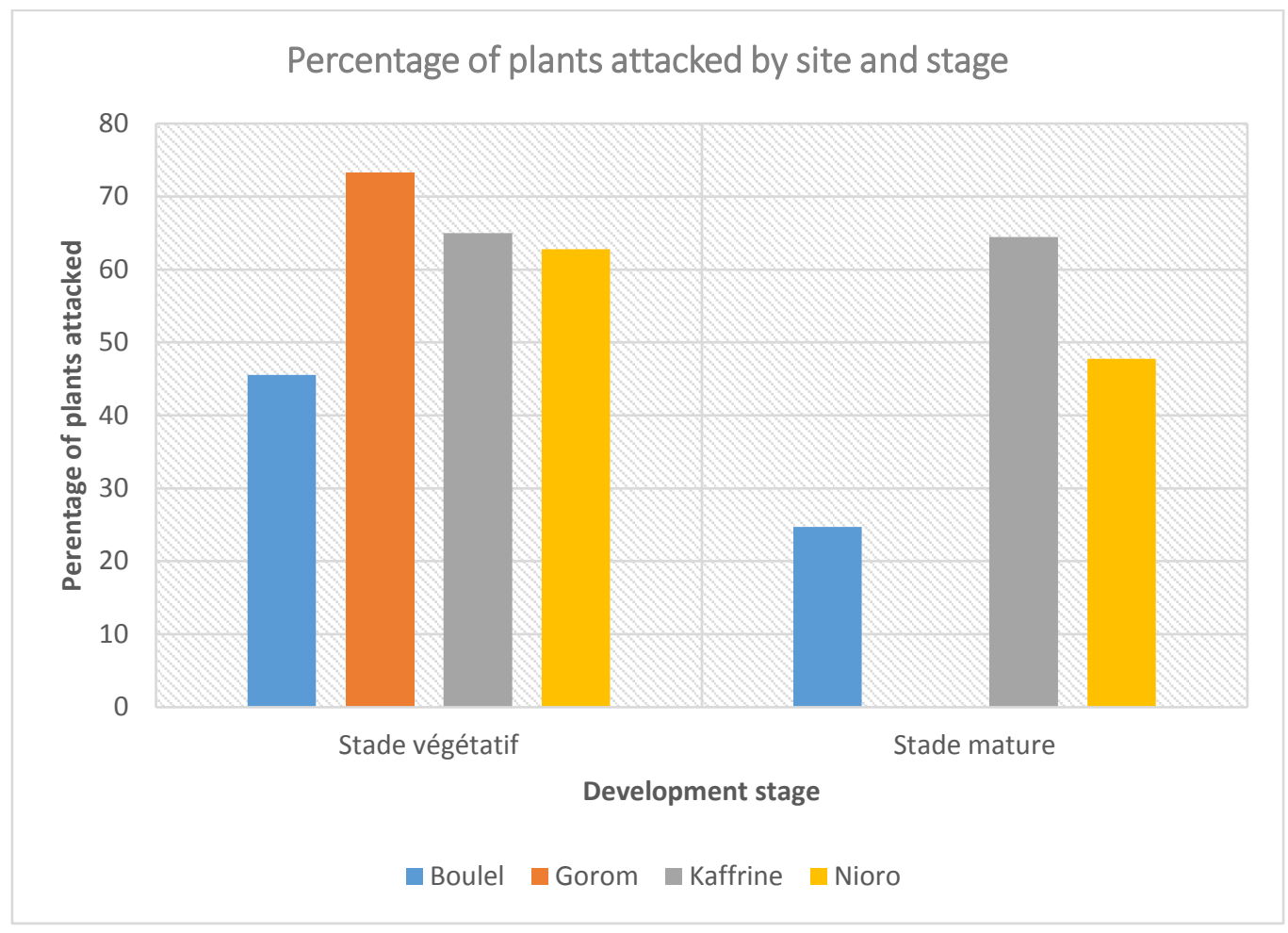

Figure 2: Percentage of plants attacked by site and stage.

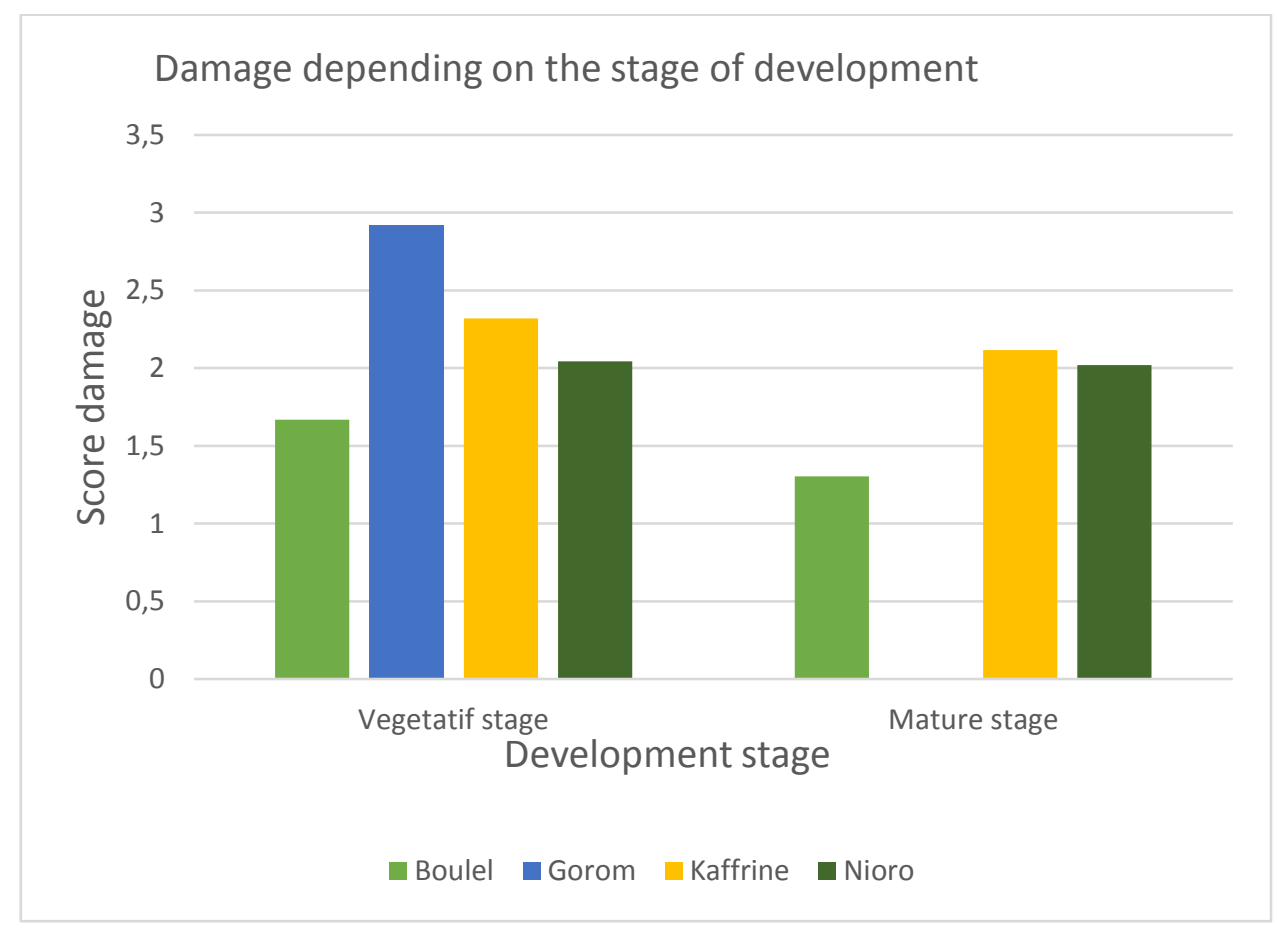

Figure 3: Damage depending on the stage of development. 


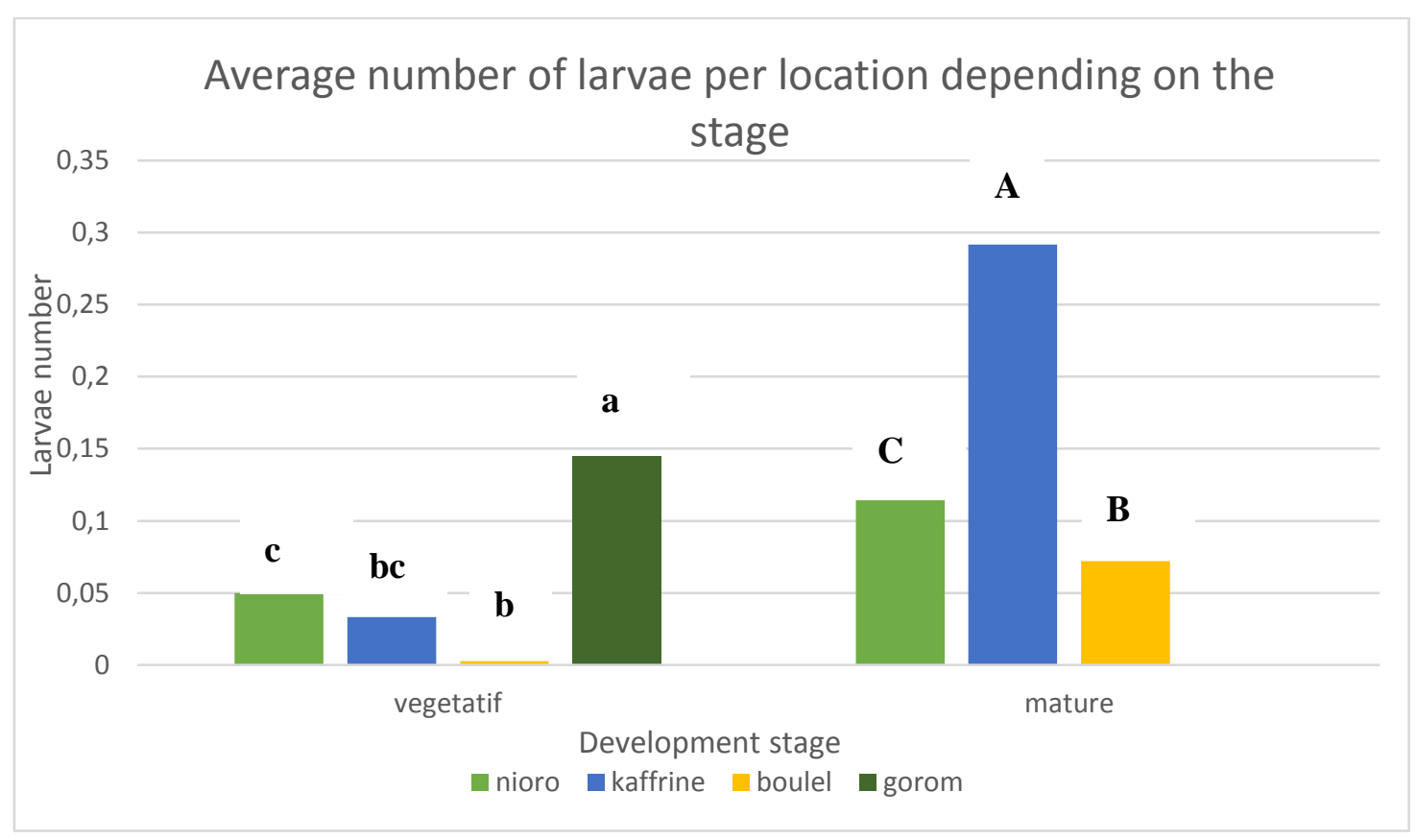

Figure 4: Average number of larvae per location depending on the stage.

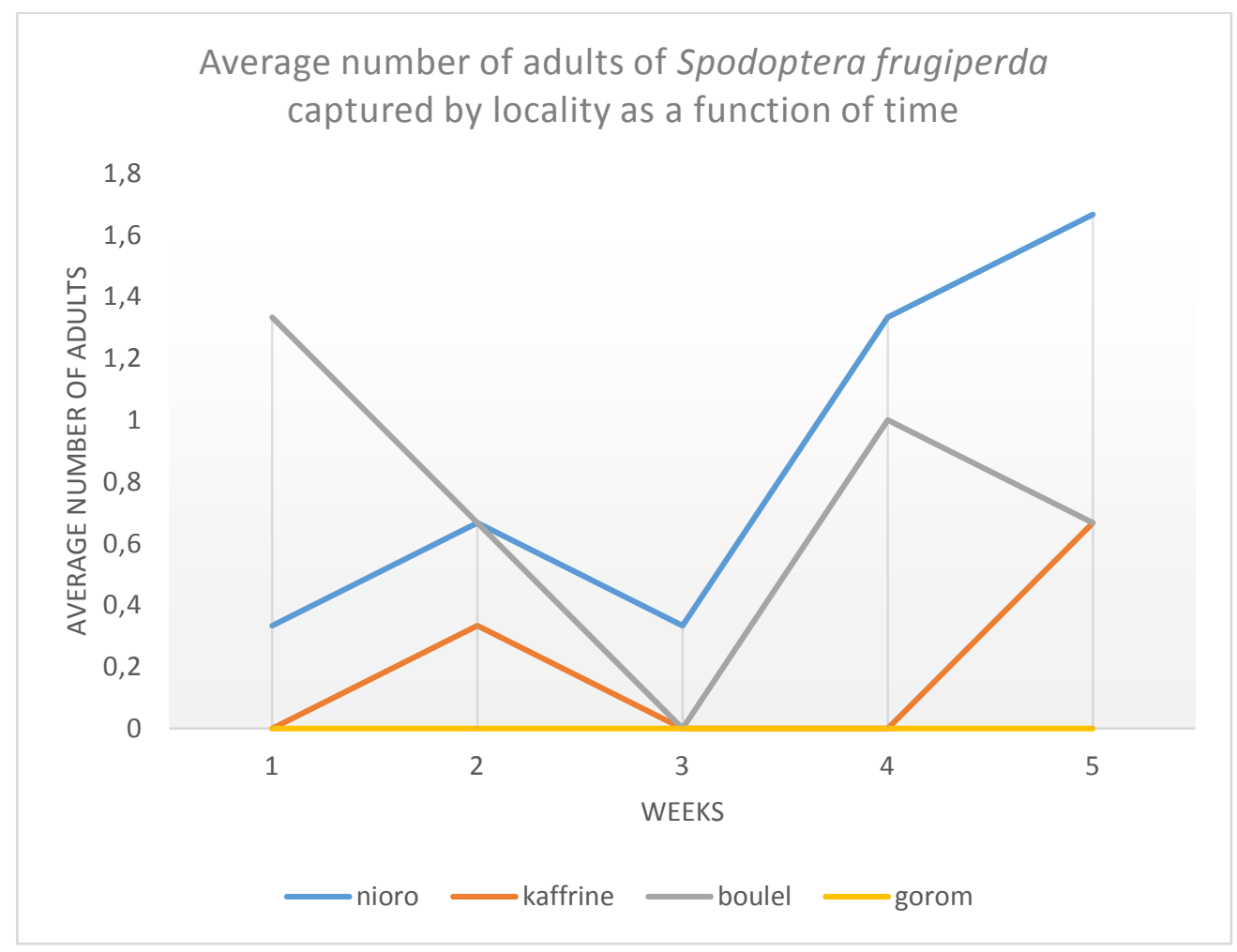

Figure 5: Average number of adults of Spodoptera frugiperda captured by locality as a function of time. 

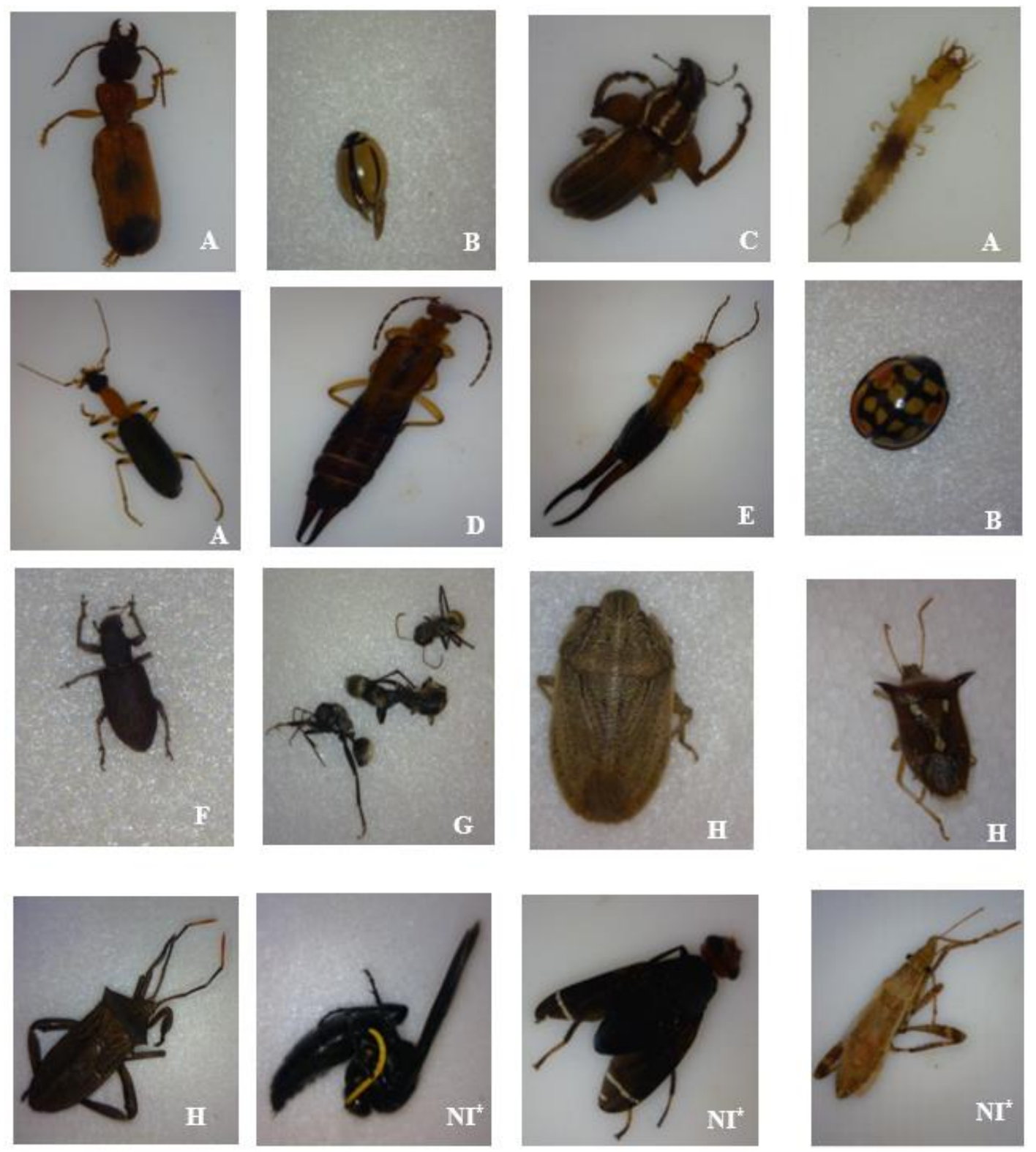

$\mathrm{A}=$ Coleoptera Carabidae, $\mathrm{B}=$ Coleoptera Coccinelidae, $\mathrm{C}=$ Coleoptera Curculionidae, $\mathrm{D}=$ Carcinophoridae, $\mathrm{E}=$ Dermaptera Forficulidae, F= Coléoptère Chrysomelidae, G= Hymenoptera Formicidae, H= Hemiptera Pentatomidae, NI*= Unidentified family.

Photo 1: Natural enemies found. 

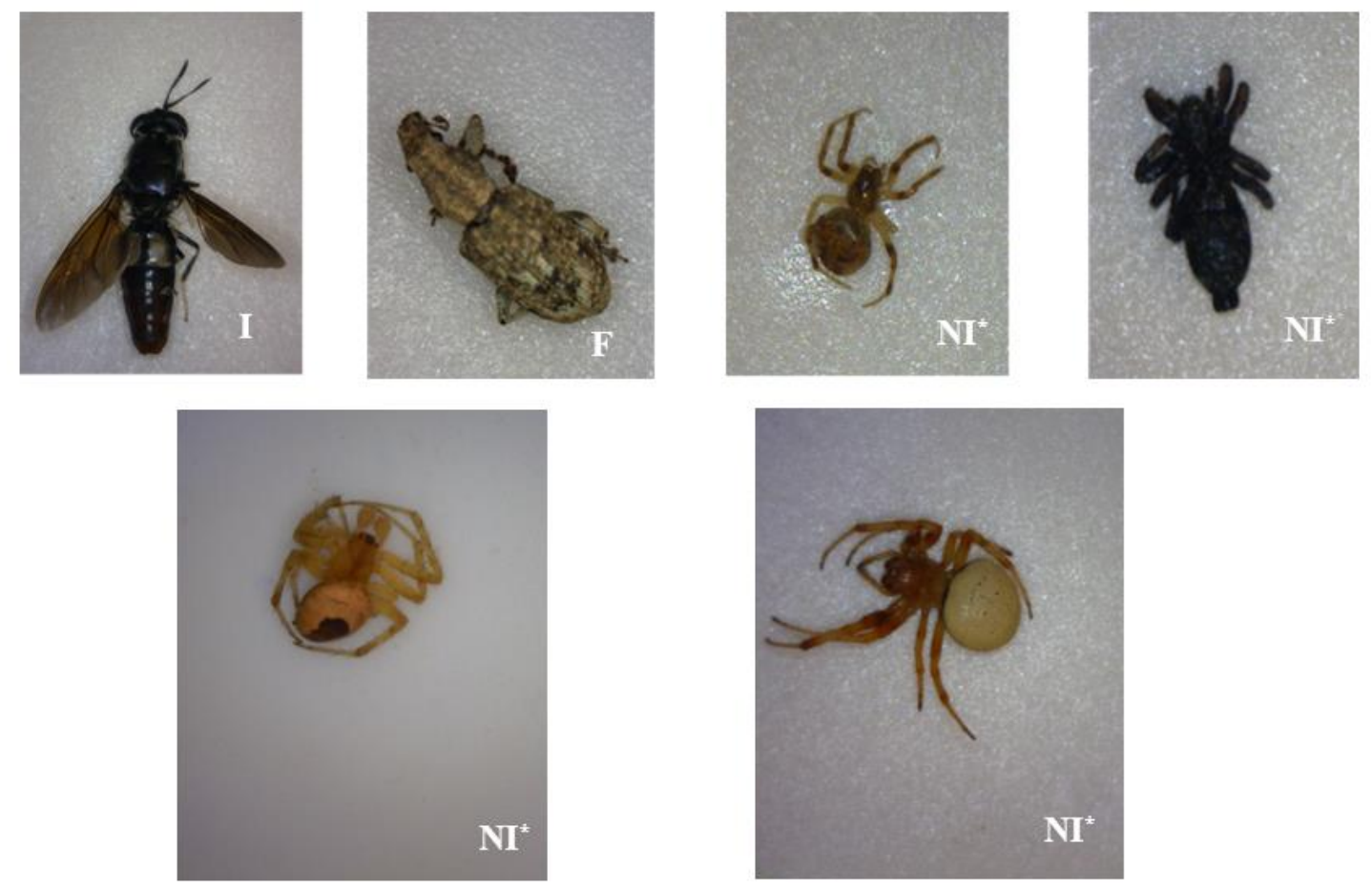

Figure 6: Predators captured.
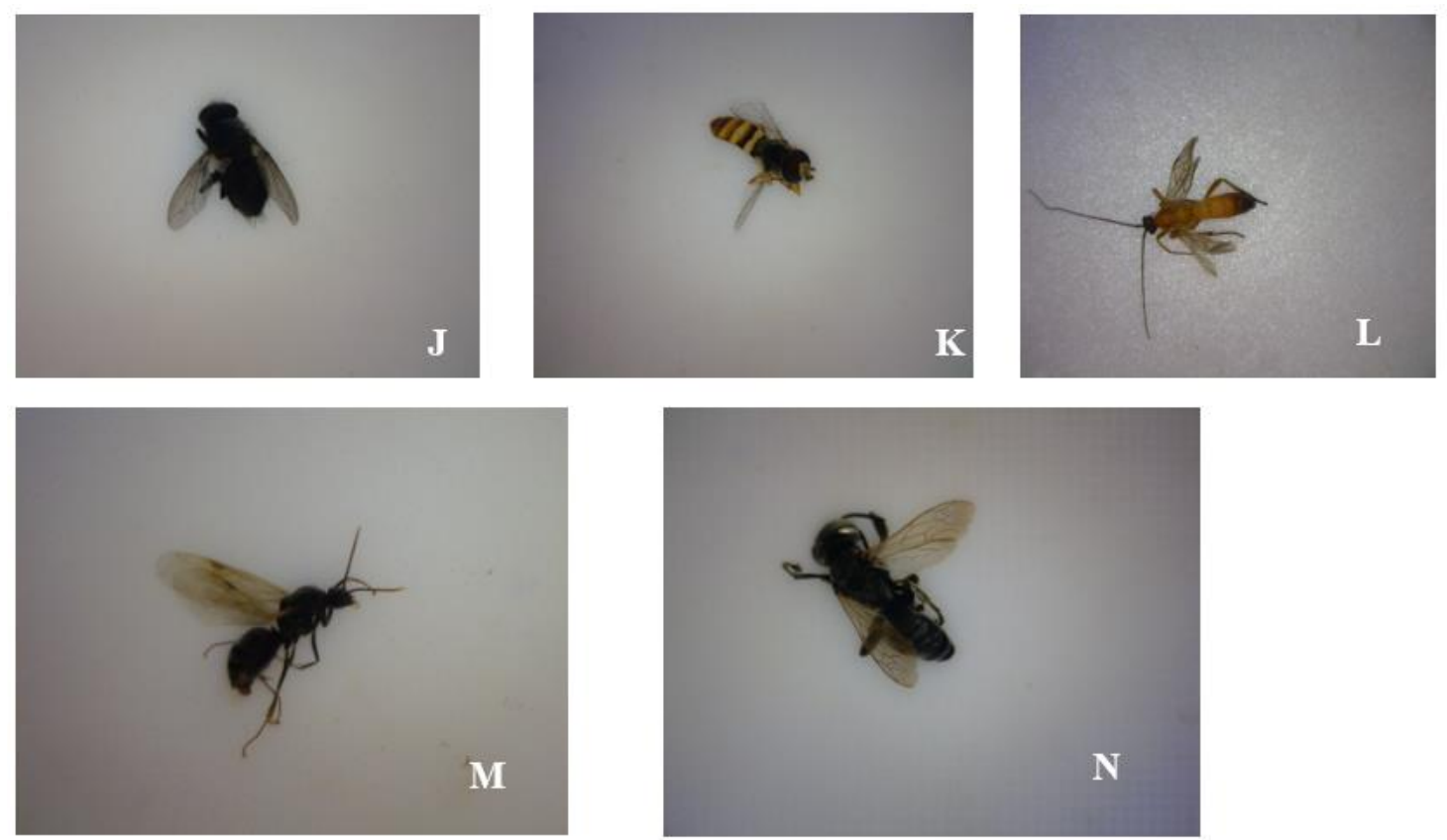

I= Diptera Stratiomyidae J= Diptera Tachinidae, $\mathrm{K}=$ Diptera Syrphidae, L= Hymenoptera Braconidae, M= Hymenoptera Scoilidae, N= Hymenoptera Sphecidae, NI*= Unidentified family

Figure 7: Emerged parasitoids in laboratory. 
Table 2: Natural enemies of Spodoptera frugiperda identified at family level.

\begin{tabular}{|c|c|c|c|c|}
\hline \multicolumn{5}{|c|}{ Natural enemies recorded and captured by locality } \\
\hline Order & Family & Host Plant & Status & Number of individuals \\
\hline & & Nioro & & $\begin{array}{l}109(41 \text { recorded et } 68 \\
\text { recorded })\end{array}$ \\
\hline \multirow{4}{*}{ Coleoptera } & Curculionidae & Maize & Predator & 6 \\
\hline & Chrysomelidae & Maize & Predator & 1 \\
\hline & Carabidae & Maize & Predator & 5 \\
\hline & NI* & Maize & Potential Predator & 6 \\
\hline Diptera & Tachinidae & Maize & Parasitoids & 40 \\
\hline \multirow[t]{2}{*}{ Dermaptera } & Forficulidae & Maize & Predator & 6 \\
\hline & & Kaffrine & & $\begin{array}{l}82 \text { ( } 45 \text { recorded et } 37 \\
\text { captured) }\end{array}$ \\
\hline \multirow{4}{*}{ Coleoptera } & Coccinellidae & Maize & Predator & 1 \\
\hline & Chrysomelidae & Maize & Predator & 15 \\
\hline & Carabidae & Maize & Predator & 3 \\
\hline & NI* & Maize & Potential Predator & 2 \\
\hline \multirow[t]{2}{*}{ Diptera } & Tachinidae & Maize & Parasitoid & 9 \\
\hline & Syrphidae & Maize & Parasitoid & 3 \\
\hline Dermaptera & Carcinophoridae & Maize & Predator & 2 \\
\hline \multirow[t]{2}{*}{ Hymenoptera } & Scoilidae & Maize & Parasitoid & 2 \\
\hline & & Boulel & & $\begin{array}{c}55 \text { (37 recorded et } 18 \\
\text { captured) }\end{array}$ \\
\hline Coleoptera & Carabidae & Maize & Predator & 4 \\
\hline Diptera & Syrphidae & Maize & Predator & 1 \\
\hline \multirow[t]{2}{*}{ Dermaptera } & Forficulidae & Maize & Predator & 3 \\
\hline & Carcinophoridae & Maize & Predator & 2 \\
\hline \multirow[t]{2}{*}{ Hemiptera } & Pentatomidae & Maize & Predator & 1 \\
\hline & NI* & Maize & Potential Predator & 1 \\
\hline \multirow{4}{*}{ Hymenoptera } & Braconidae & Maize & Parasitoid & 2 \\
\hline & Sphecidae & Maize & Parasitoid & 1 \\
\hline & Scoilidae & Maize & Parasitoid & 1 \\
\hline & NI* & Maize & $\begin{array}{l}\text { Potential } \\
\text { Parasitoid }\end{array}$ & 1 \\
\hline \multirow[t]{2}{*}{ Araneae } & NI* & Maize & Predator & 1 \\
\hline & & Gorom & & $\begin{array}{c}95 \text { (55 recorded et } 40 \\
\text { captured) }\end{array}$ \\
\hline Diptera & Stratiomyidae & Maize & $\begin{array}{l}\text { Potential } \\
\text { Parasitoid }\end{array}$ & 1 \\
\hline \multirow[t]{2}{*}{ Coleoptera } & Carabidae & Maize & Predator & 4 \\
\hline & Coccinellidae & Maize & Predator & 7 \\
\hline \multirow[t]{2}{*}{ Hymenoptera } & Formicidae & Maize & Predator & 3 \\
\hline & $\mathrm{NI} *$ & Maize & Potential Predator & 1 \\
\hline Hemiptera & Pentatomidae & Maize & Predator & 20 \\
\hline \multirow{3}{*}{ Araneae } & NI* & Maize & Predator & 1 \\
\hline & NI* & Maize & Predator & 1 \\
\hline & NI* & Maize & Predator & 3 \\
\hline
\end{tabular}




\section{DISCUSSION}

The percentages of plants attacked are important for both stages even if the damage scores evaluated according to the scale of Davis et al. (1992) remain low. This low damage could be explained by the abundance of rains between August and September. In fact, according to observations made in the field, heavy precipitation affects the populations of S. frugiperda. During the rains, the whorled leaves where the caterpillars shelter are filled with water causing mortalities on the one hand and on the other hand the larvae that have fallen to the ground come into contact with entomopathogenic microorganisms such as nematodes as described by Early et al. (2018).

The average number of larvae is greater in Gorom in the vegetative stage and in Kaffrine in the mature stage. This result could be explained by the lack of auxiliaries, in particular entompathogenic nematodes, noted at nioro.

The average number of adults of Spodoptera frugiperda captured per trap is relatively low throughout the study period in the central zone as shown by the studies of Cokola (2019) and Kouanda (2020). The absence of capture noted in Gorom could be due to the different climatic conditions between the two study areas but also the presence of other cultivated hosts, the cultivation method and the small size of the plot.

In this study, the natural enemies of $S$. fruigiperda identified on maize are mainly predators, parasitoids and entomopathogenic nematodes, and predators are the most represented (see table).

The Carabidae, Coccinellidae, Carcinophoridae, Forficulidae, Formicidae families have been found in the Center zone as in the Niayes zone. On the other hand, the families of Chrysomelidae, Curcilionidae, Tachinidae, Braconidae, Syrphidae, Scolidae and Sphecidae were found only in the central zone.

Coccinellidae and Forficulidae are known to be egg predators (Hoballah et al., 2004), Carabidae and Formicidae attack the larval stage (Lundgren et al., 2010) while the status of Curculionidae and Chrysomelidae are described as predators eggs and young larvae (Cokola, 2019). The species of the Tachinidae, Syrphidae, Scoilidae, Braconidae, Sphecidae and Stratiomyidae family are formidable parasitoids found in the two agro-ecological zones.

Endoparasitic nematodes emerged from S. frugiperda larvae collected at Nioro. Of a total of 132 S. frugiperda larvae collected, 50 larvae died from infestation by these nematodes. This gives an estimated parasitism rate of $38.46 \%$. The parasitism rate was equal to the mortality rate because all parasitized larvae were dead. The emergence of an average of 4 individuals per host was observed. A maximum of 17 individuals per larva was found. The fall armyworm $S$. frugiperda has a high susceptibility to parasitism from these nematodes. In addition, powdery white spores of a fungus were noted on a corpse of $S$. frugiperda.

\section{Conclusion}

This work, approached within the framework of the integrated management of the fall armyworm Spodoptera frugiperda for sustainable food security in two agroecological zones (center and niayes) in Senegal (KAFACI FAW), aimed to assess the level of pest damage on corn and to determine its association with native natural enemies. The results of the monitoring made it possible to measure the incidence of pests and diseases through the percentages of plants attacked, important for the two stages of development and for the two agro-ecological zones, to assess the low severity of attack through the Davis scale. The observations also allowed to know 
the average number of larvae, important at the vegetative stage in Gorom and Kaffrine at the mature stage and the pheromone traps installed captured a low average number of adults of $S$. frugiperda throughout the study period. Several natural enemies (predators and parasitoids) have been identified down to the family, and entomopathogenic organisms (nematodes) have emerged from S. frugiperda larvae from Nioro during rearing in the laboratory. The noted parasitism rate estimated at $38.46 \%$ justifies the low larval population of Nioro compared to other sites, and therefore promising endoparasites in the biological management of FAW. In addition, there is the development of an unidentified strain of entomopathogenic fungus which opens up other avenues for research on biological control agents.

\section{COMPETING INTERESTS}

The authors declare that they have no competing interests.

\section{AUTHORS' CONTRIBUTIONS}

AN contributed to the coordination of activities, definition of experimental protocols, statistical data analysis and article writing. MF contributed to the definition of experimental protocols, field data collection, statistical analysis of data and the writing of the article. IB contributed to definition of experimental protocols, the field data collection, statistical analysis of data and the writing of the article. ID contributed to the definition of experimental protocols, field data collection statistical analysis of data and the writing of the article. PMS contributed to the manuscript correction.

\section{ACKNOWLEDGMENTS}

We would also like to thank all the farmers of the central zone and the Niayes zone, whose support was essential for the accomplishment of this work.

\section{REFERENCIES}

Abrahams P, Beale T, Cock M, Corniani N, Day R, Godwin J, Murphy S, Richards G, Vos J. 2017. Impacts and control options in Africa: Preliminary Evidence Note (April 2017) p. 18.

Ayala O, Navarro F, Virla EG. 2013. Evaluation of the attack rates and level of damages by the fall armyworm, Spodoptera frugiperda (Lepidoptera: Noctuidae), affecting corn-crops in the northeast of Argentina. Revista de la Facultad de Ciencias Agrarias. https://www.researchgate.net/publication /260837604

Baudron F, Zaman-Allah MA, Chaipa I, Chari N, Chinwada P. 2019. Understanding the factors influencing fall armyworm (Spodoptera frugiperda J.E. Smith) damage in African smallholder maize fields and quantifying its impact on yield. A case study in Eastern Zimbabwe. Crop Protection, 120: 141-150. DOI: https://doi.org/10.1016/j.cropro.2019.01. 028.

Brévault T, Ndiaye A, Badiane D, Bal AB, Sembène M, Silvie $P$, Haran J. 2018. First records of the fall armyworm, Spodoptera frugiperda (Lepidoptera: Noctuidae), in Senegal. Entomologia Generalis, 37(2) : 129-142.

DOI: https://doi.org/10.1127/entomologia/201 $8 / 0553$.

Camara M, Mbaye AA, Samba SAN, Gueye T, Noba K, Diao S, Cilas C. 2013. Etude de la productivité et de la sensibilité de diverses variétés de tomate (Lycopersicon esculentum Mill) à la virose du jaunissement et de l'enroulement en cuillère des feuilles au Sénégal. Int. J. Biol. Chem. Sci., 7: 2504-2512. DOI: https://doi.org/10.4314/ijbcs.v7i6.25.

Camara M, Mbaye AA, Samba SAN, Gueye T, Noba K, Diao S, Cilas C. 2013. Èvaluation de la virose du jaunissement et 
de l'enroulement en cuillere des feuilles de tomate (Lycopersicon esculentum Mill) sur divers cultivars au Senegal. African Journal of Science and Technology, 12(2): 91-98. DOI: https://www.ajol.info/index.php/ajst/artic le/view/155986

Cokola CM. 2019. Monitoring, caractérisation moléculaire et lutte biologique contre Spodoptera frugiperda (Lepidoptera: Noctuidae) (Master Thesis). Université de Liège Gembloux Agro-Bio, Liège, $\mathrm{p}$. 74.

Early R, González-Moreno P, Murphy ST, Day

R. 2018. Forecasting the global extent of invasion of the cereal pest Spodoptera frugiperda, the fall armyworm. NeoBiota, 40: 25-50. DOI: https://doi.org/10.3897/neobiota.40.2816 5.

Germain JF, Goergen G, Reynaud P, Silvie P. 2017. Une noctuelle américaine envahit l'Afrique. Phytoma, 34-37.

Goergen G, Kumar PL, Sankung SB, Togola A, Tamò M. 2016. First Report of Outbreaks of the Fall Armyworm Spodoptera frugiperda (J E Smith) (Lepidoptera, Noctuidae), a New Alien Invasive Pest in West and Central Africa. PLOS ONE, 11: e0165632.

DOI: https://doi.org/10.1371/journal.pone.016 5632.

Harrison RD, Thierfelder C, Baudron F, Chinwada P, Midega C, Schaffner U, Van den Berg J. 2019. Agro-ecological options for fall armyworm (Spodoptera frugiperda JE Smith) management: Providing low-cost, smallholder friendly solutions to an invasive pest. Journal of Environmental Management, 243: 318330. DOI: https://doi.org/10.1016/j.jenvman.2019.0 5.011 .

Hoballah ME, Degen T, Bergvinson D, Savidan A, Tamò C, Turlings TCJ. 2004.
Occurrence and direct control potential of parasitoids and predators of the fall armyworm (Lepidoptera: Noctuidae) on maize in the subtropical lowlands of Mexico. Agricultural and Forest Entomology, 6: $83-88 . \quad$ DOI: https://doi.org/10.1111/j.14619555.2004.00207.

Kouanda N. 2020. Monitoring et méthodes alternatives de lutte contre Spodoptera frugiperda J.E Smith dans la région du Centre-Ouest du Burkina Faso (Master Thesis). Université de Liège Gembloux Agro-Bio, Liège, p. 86.

López-Edwards M, Hernández-Mendoza JL, Pescador-Rubio A, Molina-Ochoa J, Lezama-Gutiérrez R, Hamm JJ, Wiseman BR. 1999. Biological Differences between Five Populations of Fall Armyworm (Lepidoptera: Noctuidae) Collected from Corn in Mexico. The Florida Entomologist, 82: 254-262. DOI: https://doi.org/10.2307/3496577.

Lundgren JG, Toepfer S, Haye T, Kuhlmann U. 2010. Haemolymph defence of an invasive herbivore: its breadth of effectiveness against predators. Journal of Applied Entomology, 134: 439-448.

Malanno K, Christophe KK, Gouzou DRJ, Norbert BKK, Germain OO. 2019. Détection de la Chenille Légionnaire d'automne, Spodoptera frugiperda (J. E. Smith, 1797) (Coleoptera : Noctuidae) et Premières Observations sur sa Biologie en Côte d'Ivoire. ESJ, 15(12): 332. DOI: https://doi.org/10.19044/esj.2019.v15n12 p332.

Mitchell ER. 1979. Monitoring Adult Populations of the Fall Armyworm. The Florida Entomologist, 62: 91-98. DOI: https://doi.org/10.2307/3494085.

Montezano DG, Specht A, Sosa-Gómez DR, Roque-Specht VF, Sousa-Silva JC, Paula-Moraes SV, Peterson JA, Hunt TE. 2018. Host Plants of Spodoptera frugiperda (Lepidoptera: Noctuidae) in 
the Americas. Afen, 26: 286-300. DOI: https://doi.org/10.4001/003.026.0286.

Prasanna BM, Huesing JE, Eddy R, Peschke VM. n.d. Fall Armyworm in Africa. 2018. A Guide for Integrated Pest Management, 120.

Rwomushana I, Bateman M, Beale T, Beseh P, Cameron K, Chiluba M, Clottey V, Davis T, Day R, Early R, Godwin J, GonzalezMoreno P, Kansiime M, Kenis M, Makale F, Mugambi I, Murphy S, Nunda W, Phiri N, Pratt C, Tambo J. 2018. Fall armyworm: impacts and implications for Africa. Fall armyworm: impacts and implications for Africa.

Sharanabasappa Kalleshwaraswamy CM, Maruthi MS, Pavithra HB. 2018. Biology of invasive fall army worm Spodoptera frugiperda (J.E. Smith) (Lepidoptera: Noctuidae) on maize. Ind. J. Entomol.,
80:

540.

DOI:

https://doi.org/10.5958/0974-

8172.2018.00238.9.

Yu SJ. 1991. Insecticide resistance in the fall armyworm, Spodoptera frugiperda (J. E. Smith). Pesticide Biochemistry and Physiology, 39: 84-91. DOI: https://doi.org/10.1016/00483575(91)90216-9.

Zhao YX, Huang JM, Ni H, Guo D, Yang FX, Wang X, Wu SF, Gao CF. 2020. Susceptibility of fall armyworm, Spodoptera frugiperda (J.E. Smith), to eight insecticides in China, with special reference to lambda-cyhalothrin. Pesticide Biochemistry and Physiology, 168: $\quad 104623 . \quad$ DOI: https://doi.org/10.1016/j.pestbp.2020.10 4623. 